\title{
On the influence of magnetization on the constants of elasticity in iron
}

\section{A. Bock}

To cite this article: A. Bock (1895) On the influence of magnetization on the constants of elasticity in iron, Philosophical Magazine Series 5, 39:241, 548-548, DOI: 10.1080/14786449508620755

To link to this article: http://dx.doi.org/10.1080/14786449508620755

Published online: 08 May 2009.

Submit your article to this journal ¿

Wlll Article views: 2

Q View related articles $₫$ 
(2) If the magnetic lines of force are at right angles to the longitudinal direction of the wire projecting into the field, the tractive force at right angles to the lines of force is smaller in iron than the force $p \sharp$. The ratio $p \sharp / p \perp$ (where $p \sharp$ and $p \perp$ are the tractive forces parallel and at right angles to the lines of force respectively), which with mean strengths (about $\mathrm{H}=100$ ) is greater than 100 , rapidly decreases as the field increases and appears to approach unity.-Wiedemann's Annalen, No. 1, 1895.

\section{ON THE INFLUENCE OF MAGNETIZATION ON THE CONSTANTS OF ELASTICITY IN IRON. BY A. BOCK.}

The result of this research is stated as follows by the author:By magnetization the constants of elasticity of soft iron, the modulus of torsion, and the modulus of elasticity are certainly not altered by more than $\frac{1}{2}$ per cent. The series of observations indicate that the flexure diminishes, at the same time the torsion seems also to diminish, while the ratio of the lateral contraction to the longitudinal expansion increases. Iron is more incompressible in the magnetic field. Nothing can be alleged with certainty as to magnetized steel bars. These results are in perfect agreement with the well-known investigations of G. Wiedemann, and they may be deduced from the theory propounded by that author on the assumption of rotating molecular nagnets.-Wiedemann's Annalen, No. 3, 1895.

\section{ON THE MAGNETIZATION OF IRON BY VERY SMALL FOROES.} BY WERNER SCHMIDT.

The experimental results of this research are given by the author in the following statements :-

1. Steel follows small magnetizing forces more rapidly than iron.

2. The magnetization function $\kappa$ of mild steel is greater for small forces than that of iroll. In the present case $\kappa$ (steel) is to $\kappa$ (iron) as 4 is to 3 . The stronger maguetization ordinarily observed in iron is only met with in greater magnetizing forces, for instance, $\mathrm{H}>1$.

3. The constancy of the magnetizing function $\kappa$ for very small forces, first observed by Lord Rayleigh, is confirmed. The boundary of proportionality between magnetizing forces and magnetic moments may be taken with sufficient accuracy for technical purposes as near the magnetizing force $H_{1}=0.06$. This value represents a rather sudden transition in the curve $\kappa=f\left(\mathrm{H}_{1}\right)$. Below this the deviations from proportionality are only very feeble, that is the curve $\kappa=f\left(\mathrm{H}_{1}\right)$ passes into a parallel to the $\mathrm{H}$-axis. The point at which it can be identified with a straight line (parallel) is different according to the nature of the iron investigated, and especially according to the sensitiveness of the apparatus used for the measurements, without varying much from a certain mean value which may be regarded as lying between the magnetizing forces $\mathrm{H}_{1}=0.03$ and 0.04 . Wiedemann's Annalen, No. 4, 1895. 